\title{
Pilot study on the Non-Invasive Detectability of Femoral Neck Fractures with Frequency Response Functions
}

\author{
Wolfgang Witteveen ${ }^{1}$, Carina Wagner ${ }^{1}$, Patrick Jachs ${ }^{2}$, Stefan Froschauer ${ }^{2}$, Harald Schöffl2 \\ ${ }^{1}$ Upper Austrian University of applied Sciences, Wels, Austria \\ ${ }^{2}$ BioMed-zet Life Science GmbH, Linz, Austria \\ Email: wolfgang.witteveen@fh-wels.at
}

Received 30 April 2014; revised 27 May 2014; accepted 23 June 2014

Copyright (C) 2014 by authors and Scientific Research Publishing Inc.

This work is licensed under the Creative Commons Attribution International License (CC BY). http://creativecommons.org/licenses/by/4.0/

(c) (i) 0pen Access

\begin{abstract}
A suspicion of a femoral neck fracture is a frequently recurring situation, especially in nursing homes. For the clarification of such a suspicion normally imaging techniques are used. Such equipment is expensive and therefore is located in hospitals. In addition to the costs, a transport causes stress for the patient. This pilot study is devoted to the question whether the detection of a femoral neck fracture with vibration measurements is possible in principal. In such a case, the clarification could be done on-site by an ordinary person using much cheaper equipment. This would reduce the stress for the patient and save money. For this purpose vibration measurements on a dead body with intact, with partially fractured and with complete cut femoral neck have been performed. Two different methods for the vibration initiation have been investigated, the so called impact testing and the shaker testing. The frequency response function has been determined for all combinations on both sides of the body. It turned out that there is a clear difference in the frequency response functions of the fractured bone with respect to the intact bone when shaker testing is used. This indicates that the method could have the potential to be a cost-saving alternative to imaging techniques. However, in a next step a statistically reliable clinical survey on living persons needs to be done.
\end{abstract}

\section{Keywords}

Biomechanics, Vibrations, Frequency Response Function, FRF, Femoral Neck Fracture

\section{Introduction}

The vibrations of a solid body can be characterized by its resonant frequencies and the according deflection

How to cite this paper: Witteveen, W., Wagner, C., Jachs, P., Froschauer, S. and Schöffl, H. (2014) Pilot study on the NonInvasive Detectability of Femoral Neck Fractures with Frequency Response Functions. World Journal of Mechanics, 4, 210216. http://dx.doi.org/10.4236/wjm.2014.47022 
shapes which are called vibration modes, see Maia [1] and Ewins [2]. The latter quantities are mainly system parameters which are dominated by a body's stiffness and mass distribution. A crack inside a solid body represents a change in stiffness which may lead to a change in the resonant frequency (=eigenfrequency) and in the mode form. This observation is applicable to bones as well. This work is devoted to an answer on the question, whether a femoral neck fracture modifies the bones eigenfrequencies so much that it can be measured. If so, it would be possible to detect a femoral neck fracture based on vibration measurements. Such a tool would be much cheaper as imaging based techniques and it could be applied on-site by an ordinary person without moving the patient to another place.

The basic idea to use vibration measurements as an indicator of a bones condition is not new. A review on this approach from its beginning up to 1995 can be found in the review of Nokes [3]. In case of the tibia a lot of research confirms that the eigenfrequencies are significantly influenced by a fracture and the subsequent fracture-healing, see Cunningham et al. [4], Tower et al. [5], Nokes et al. [6], Benirschke et al. [7] and Nakatsuchi [8]. In most of the cases the frequency response function has been investigated which is a generalization of eigenfrequencies. Based on the same idea it has been investigated whether the status of integration of implants can be detected based on vibration date, see Cairns [9] and Cairns et al. [10]. In general it can be observed, that there was less focus on the femur as on the tibia. A femur related research can be found from Denker and Moberg [11] where the detectability of soft tissues between fractured bones has been investigated. Lappi et al. [12] determined some physical properties of the femur based on vibration measurements. Thomas et al. [13] observed in 1990 that the femurs eigenfrequencies depend on the amount of axial preload. Khalil et al. [14] performed vibration measurements on the embalmed human femur in order to document its vibrational characteristics. Based on the measurement data a mathematical model has been developed in order to compute the mode shape of a particular eigenfrequency. Investigations with respect to femoral neck fractures have been done by Misurya et al. [15] and Jawad, Odumala and Jones [16]. In the latter publication a vibrating tuning fork has been placed on the patella and arrived vibrations at the anterior superior iliac spine (ASIS) have been measured. It has been tried to detect the fracture by a comparison of the vibration amplitudes. It turned out, that there was a significant amplitude reduction when comparing normal to fractured hips.

The objective of this work is similar as the one of Jawad, Obdumala and Jones [16]. In contrast to the latter publications frequency response functions have been used. It is known from mechanical engineering, that such functions are much more meaningful as time data, see Maia [1] and Ewins [2]. The goal of this pilot study is to see whether there is a significant change in the frequency response functions of a dead body's femur with and without neck fracture. If so, further investigations make sense in order to set up a clinical relevant procedure.

\section{Patients and Methods}

The identification of frequency response functions (FRFs) is a standard procedure in structural dynamics, see Maia [1] and Ewins [2]. For its determination a structure has to be excited at a certain point A to vibrate. The induced force is called input. The so called output is the reaction of the structure at a point $B$. In our case this reaction is an acceleration. Note that point A may be equal to point B (or not). The input and the output signal are simultaneously measured. In a next step the recorded signals are transformed from the "time domain" into the "frequency domain". This is done by discrete Fourier transformation, see e.g. Sundararajan [17]. In the frequency domain the signals aren't sorted with respect to their chronological order but with respect to their "rapidity". This may not be that intuitive as the representation in the time domain but it is much more meaningful. A FRF can be interpreted as the quotient of output and input in the frequency domain. Note that the actual computation of a FRF is more sophisticated, but for the application of this technique the former explanation is sufficient. Obviously the FRF is a quantity in the frequency domain as well. Therefore it is a complex quantity. For its representation two quantities are necessary. The real part and the imaginary part have to be given or the amplitude and the phase. In this publication we use the second representation. In structural dynamics the so called "hammer testing" and "shaker testing" are well established.

In case of hammer (or impact) testing a hammer is used in order to induce vibrations in the structure, see Figure 1. A so called "modal hammer" is used which is equipped with a sensor, so that the induced force can be measured. In order to get a better repeatability a piece of iron sheet is pressed on the epicondyluslateralis (= Point A) via two cable retainer. Two FRFs have been determined because the patella and the epicondylusmedialis have been considered as output locations (=Point B). The sensors have been applied by hand which is suitable 


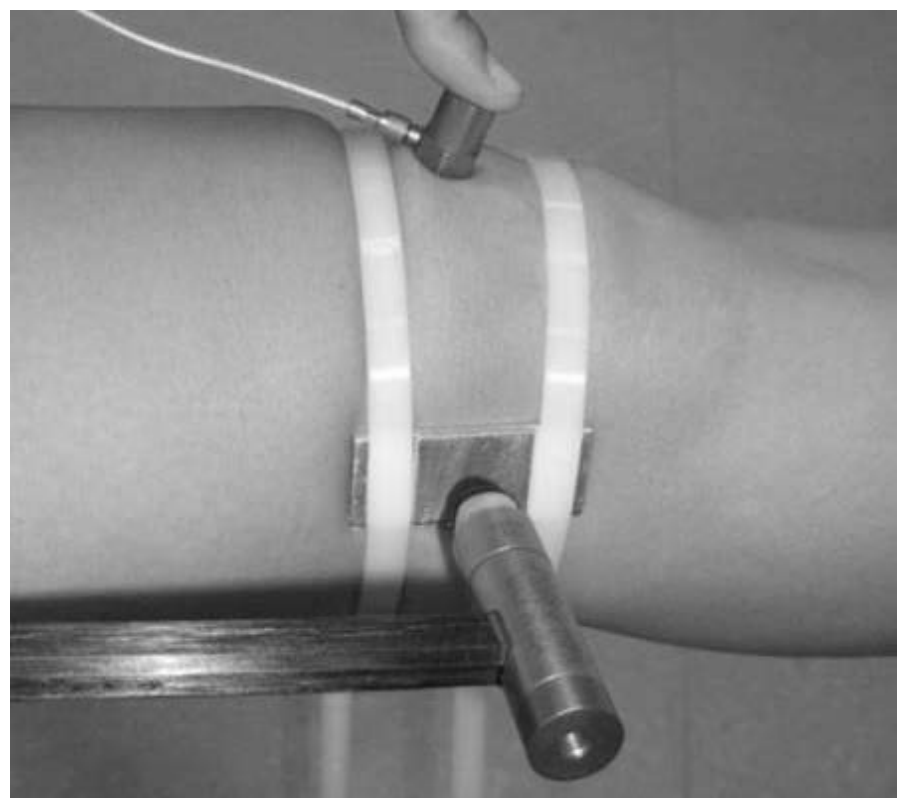

Figure 1. Hammer testing, sensor at patella.

up to a frequency of $1000 \mathrm{~Hz}$, see Ewins [2]. For each valid FRF five impact tests have been performed and averaged.

In case of shaker testing an electromechanical vibrator is used in order to induce vibrations in the structure. The vibrating part of the shaker is connected with the structure, see Figure 2. In this connection link a force sensor is mounted in order to get the time signal of the induced force. The connection link is fixed onto a piece of iron sheet which is pressed on the epicondyluslateralis (=Point A) via two cable retainer. For a better stability and repeatability a ground plate has been used. The shaker was fixed on the ground plate and the lower leg was fixated on that plate by means of a band. A sine sweep has been selected as excitation signal for the shaker. The sine sweep started at $40 \mathrm{~Hz}$ and the frequency has been continuously increased up to $800 \mathrm{~Hz}$. Three FRFs have been determined because the patella, the epicondylusmedialis and the ASIS have been considered as output locations (=Point B). The third output location has been chosen in order to get a comparison with the work of Jawad, Obdumala and Jones [16]. Again, the sensors have been applied by hand.

Impact testing is cheaper, quicker and simpler as shaker testing. On the other hand, shaker testing is more accurate especially in case of non-linear and highly damped systems. For this pilot study both methods have been applied in order to identify the better one for that kind of problem.

The used hardware can be found in Table 1. The software routines for LabView have been provided by the support of National Instruments, Austria.

The dead body was provided by the Division of Clinical and Functional Anatomy of the Medical University in Innsbruck, Austria. It was a body of a male, died with 75 years due to a colon carcinoma. There was no abnormality and a bland anamnesis in the region of the femur. The first measurements have been done with the intact bone. For the next measurements the surrounding tissue has been opened and the femur was partially fractured by an osteotom (some kind of crosscut saw). The bone (femur) was partially sawed in approximately semi-diameter nearby femoral neck by the surgeon. This was done by experience and no measurements on the actual destruction have been performed. The final measurements have been performed on the totally cut through femoral neck. All the measurements (shaker and hammer testing) have been performed on the right and the left side. At each stage of fracture and with each method three FRFs have been measured.

\section{Ethics}

The project with the registration number E-11-13 (2.1.5) has been approved by the Upper Austrian Ethic Commission (http://www.ooe-ethikkommission.at). The project was permitted without any objections on the 29th of April 2013. 
Table 1. Hardware.

\begin{tabular}{ccc}
\hline Description & Company & Model Number \\
\hline Shaker & LSD & V201/3-PA25E \\
Impact Hammer & PCB & 086C03 \\
Acceleration Sensor & Kistler & 8702B25 \\
Force Sensor & PCB & 208C01 \\
Data Acquisition & NI & cDAQ-9178 with Input Module NI9234 \\
Output (Sine Sweep for Shaker) & & cDAQ-9178 with Output Module NI9263 \\
\hline
\end{tabular}
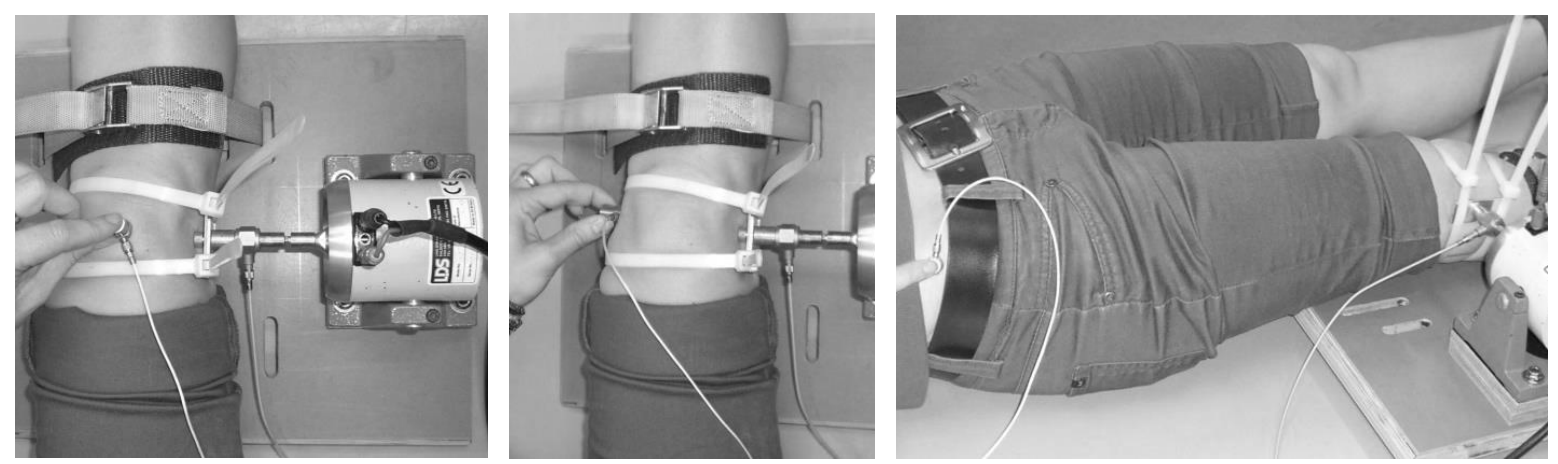

Figure 2. Shaker testing, Sensor at patella, at epicondylusmedialis and at anterior superior iliac spine (left to right).

\section{Results}

From the literature it is well known, that the repeatability is given for this kind of measurements, see Benirschke [7] for the tibia and Jurist [18] for the ulna. At first we verified/controlled our procedure weather it delivers reproducible data or not. Five test persons have been accompanied for several weeks and the hammer testing as well as the shaker testing has been performed several times. It turned out, that our set up delivers reproducible FRFs.

During all measurements it could be observed, that the FRF is trustworthy up to max. $800 \mathrm{~Hz}$. This value has been concluded by the evaluation of the coherence function, see Maia [1] and Ewins [2]. The coherence function has been provided automatically by the used software and it is an indicator of the quality of an FRF.

Figure 3 and Figure 4 contain the hammer testing FRFs obtained by the measurements off the dead body. Figures 5-7 contain the shaker testing FRFs. The black curves are the FRFs of the intact bone, the grey ones are the FRFs of the partially fractured bone and the dashed light grey curves hold FRFs of the totally cut through femoral neck.

\section{Discussion}

The FRFs of Figures 3-7 lead to the following two main conclusions:

- The FRFs obtained by impact testing (Figure 3 and Figure 4) do not indicate a clear change due to the fractured femoral neck.

- The shaker FRFs (Figures 5-7) are considerably different in case of an intact or a broken femoral neck. For all three FRFs the differences become significant at $250 \mathrm{~Hz}$ and higher. It is interesting that the FRFs of the broken bone tend to higher values. That means that the mobility of the femur increases due to the fracture for frequencies higher as $250 \mathrm{~Hz}$.

It is well known from literature that the shaker delivers more reliable results in case of non-linear of highly damped systems, see Ewins [2]. Both are true for the femur in-vivo. The non-linearity can be concluded from the observation of Thomas [13] which says that the eigenfrequency depends on the longitudinal loading of the bone. The high damping of imbedded bones is documented by several publications, see Bediz et al. [19], Van der 

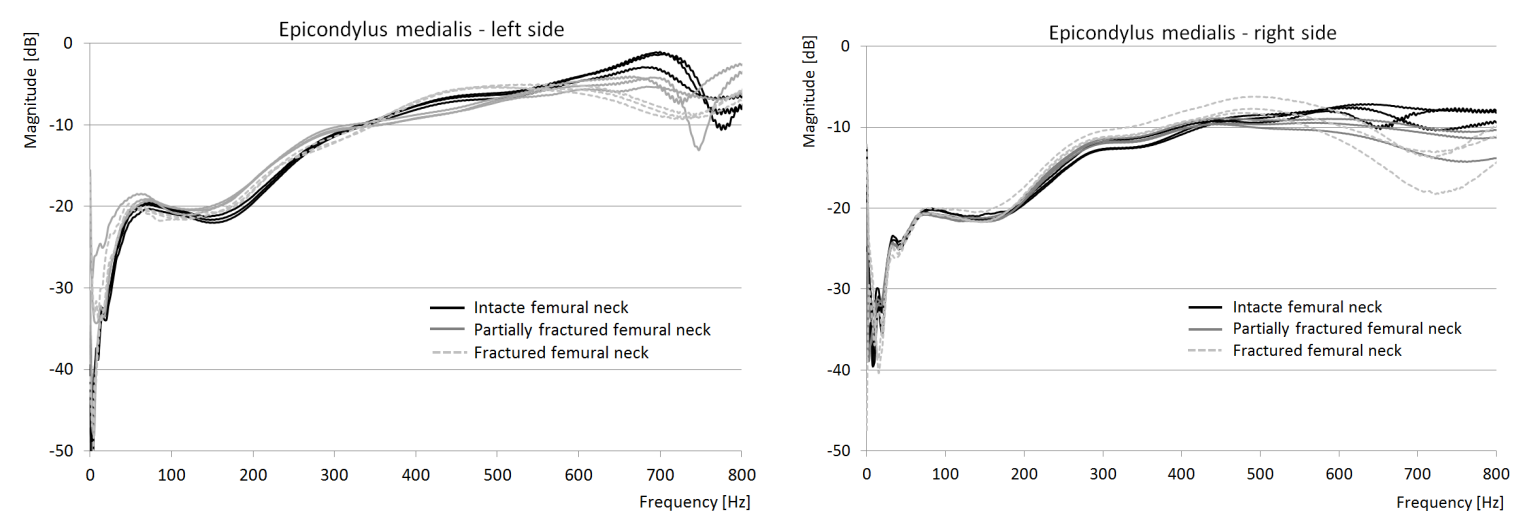

Figure 3. FRFs at epicondylusmedialis-Hammer testing of left and right leg.
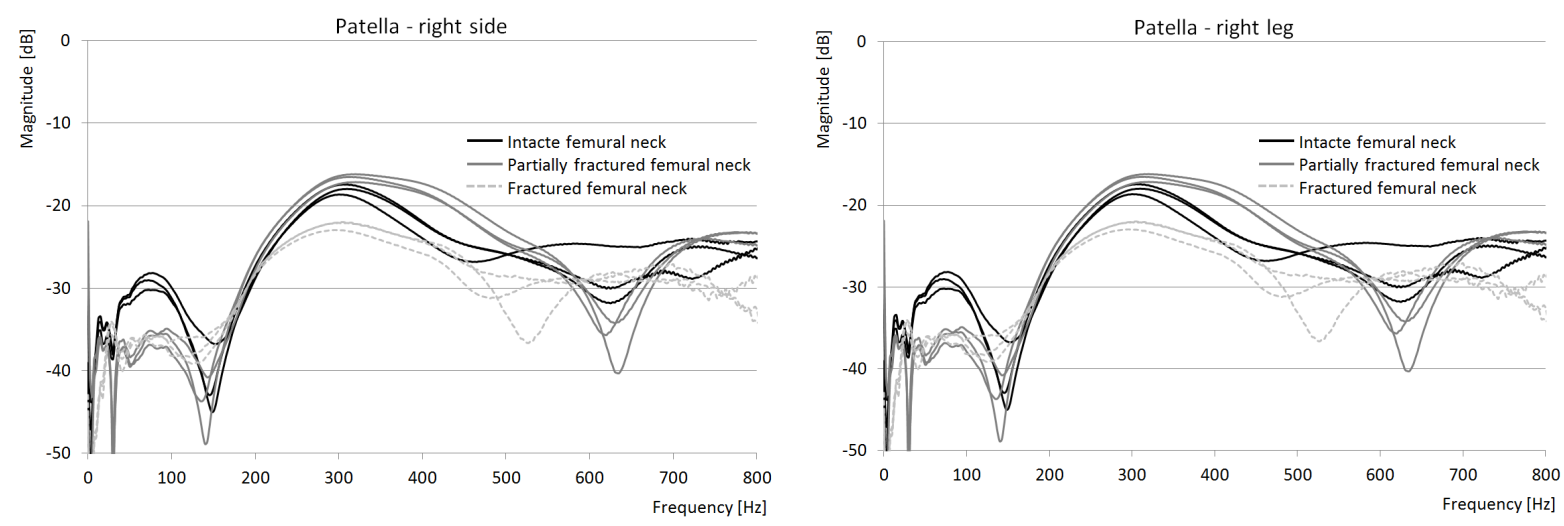

Figure 4. FRFs at patella-Hammer testing of left and right leg.
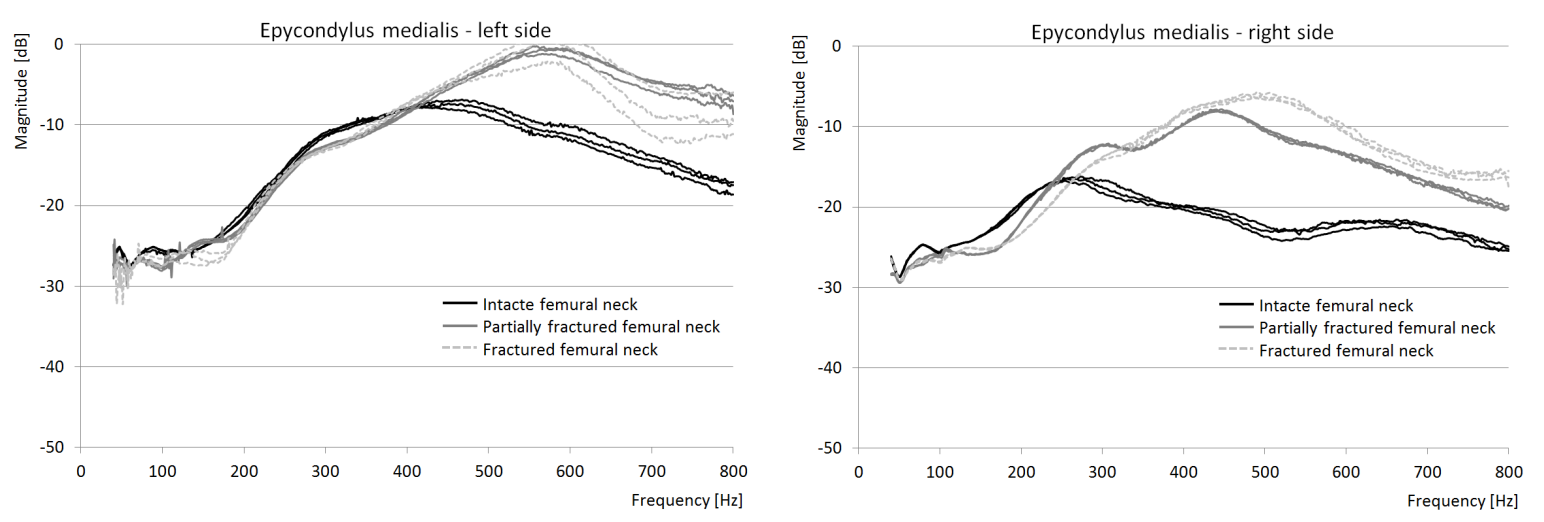

Figure 5. FRFs at epicondylusmedialis-Shaker testing of left and right leg.

Perre et al. [20] and Tsuchikane et al. [21]. Cairns et al. [10] observed a better result quality of the shaker method as well, even by in-vitro measurements.

One can receive the impression that the FRFs (shaker and hammer) obtained on the epicondylusmedialis do have the best quality in terms of amplitude and noise. This is not surprisingly because both, input and output are close together and directly located on the surface of the femur itself. This is not true when the FRF is determined on the patella or on the ASIS.

There is no consent in the literature whether the properties of the left and the right leg should be similar. Khalil et al. [14] observed significant differences on the embalmed femur whereas Benirschke [7] did not observe a remarkable difference on the tibia in-vivo. In our case it is to report that the surgeon recognized a difference in the length of the left and the right femoral neck. There was no remark on that in the person's case history and 

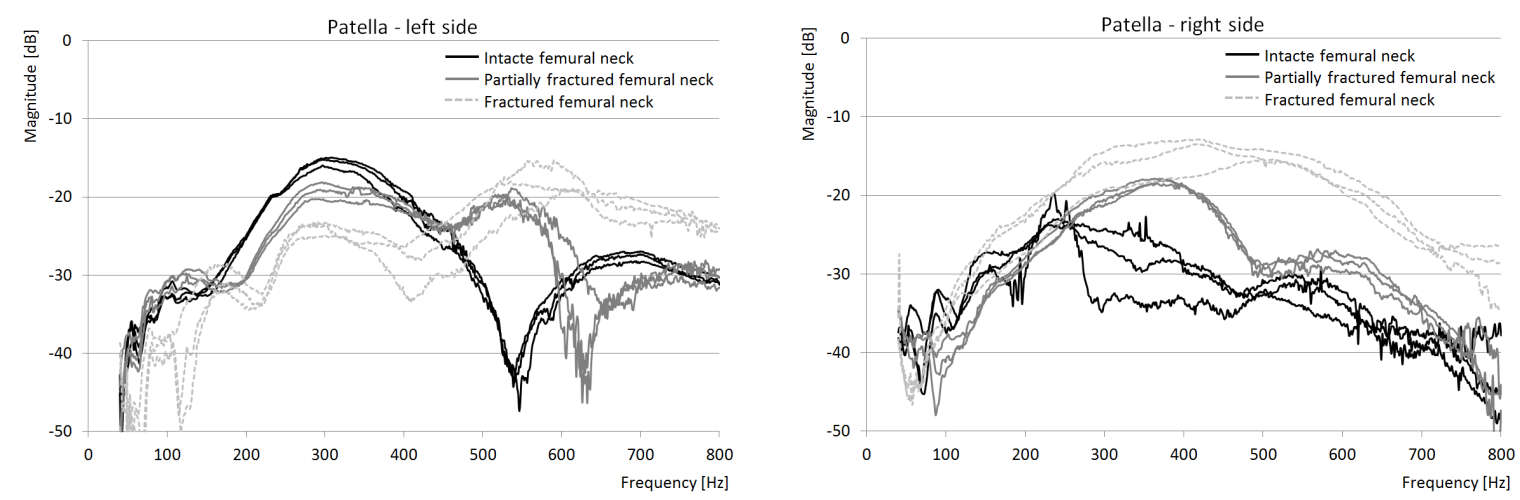

Figure 6. FRFs at patella-Shaker testing of left and right leg.
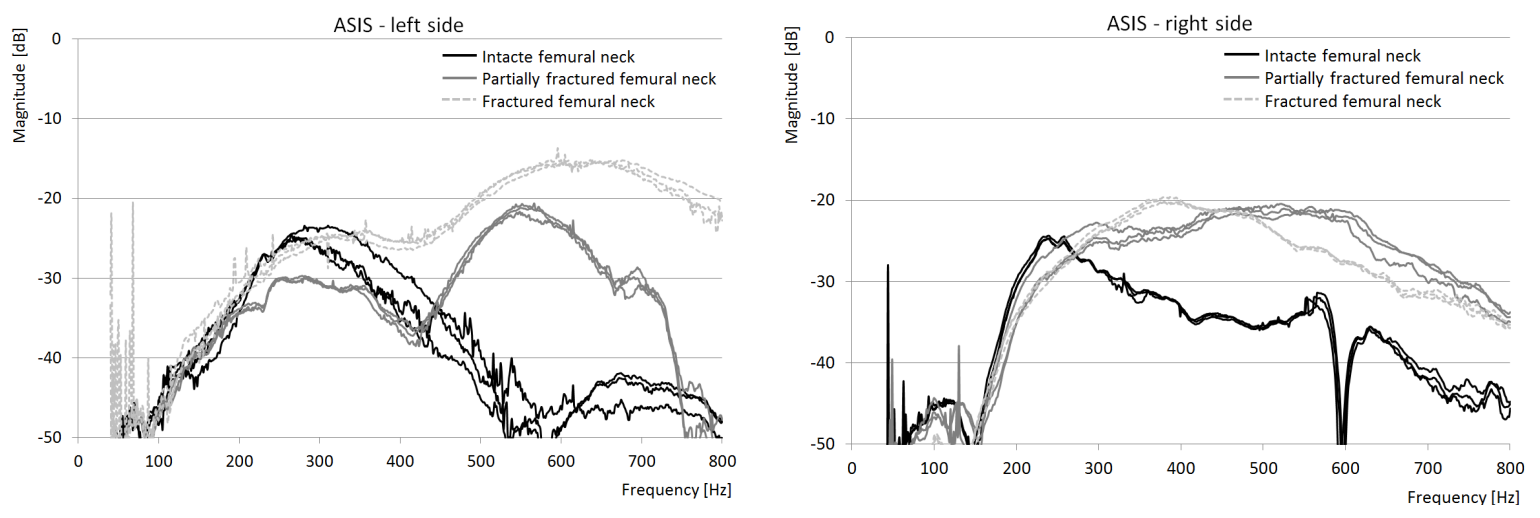

Figure 7. FRFs at ASIS - Shaker testing of left and right side.

there was no grain in the area of the femoral neck. Maybe there was an unknown old fracture of the femoral neck. Consequently, the reason for this difference is not known and no general conclusion can be drawn on the symmetry of the measurements. But the conclusion that a fracture leads to significantly different FRFs still holds.

Figure 7 needs to be discussed in the context of the observations of Jawad, Obdumala and Jones [16]. There a vibrating tuning fork is pressed on the patella. The first eigenfrequency of this tuning folk was at $128 \mathrm{~Hz}$. The thereby induced vibrations have been measured at the ASIS. It has been tried to detect the fracture by a comparison of the vibration amplitudes in case of a fractured and intact femoral neck. It turned out, that there was a significant amplitude reduction about a factor of 2 when comparing normal to fractured hips. Such a tuning folk is basically a shaker vibrating with one single frequency, even $128 \mathrm{~Hz}$. One significant advantage of the FRF approach is that instead of one frequency an entire frequency band $(40 \mathrm{~Hz}$ to $800 \mathrm{~Hz})$ is considered. This leads to much more information and Figures 5-7 indicate that frequencies higher as $250 \mathrm{~Hz}$ are better suited to detect a fracture. Another advantage of the FRF method is its objectivity. This is based on the fact, that the FRF is the quotient of output and input and not only the output, as it is the case in the publication of Jawad et al. [16]. If, for example, the input is twice as high as at another time, the FRF will lead to the same result whereas the output measurement only, will not. However, Jawad et al. [16] observed a reduction at about a factor of 2. This is equivalent to $6 \mathrm{~dB}$ when FRFs are used. The FRF value on the right leg of Figure 7 with broken femoral neck is indeed smaller than the one with intact one. On the left leg, no significant difference in the FRFs can be observed at $128 \mathrm{~Hz}$. All other FRFs have at $128 \mathrm{~Hz}$ a tendency to an amplitude reduction due to the fracture. Concluding it can be said, that the measurements indicate the most significant differences at higher frequencies and the shaker method is a generalization of the tuning fork method with significant more information.

Based on this promising pilot study a prototype of a device needs to be designed so that a statistically assured field study on living persons is possible.

\section{Conflict of Interest and Funding}

None. 


\section{Acknowledgements}

The authors wish to thank the individual who donated his body and tissues for the advancement of education and research.

\section{References}

[1] Maia, N.M.M. (Ed.) (1998) Theoretical and Experimental Model Analysis. Research Studies Press, Hertfordshire, UK.

[2] Ewins, D.J. (2000) Modal Testing. 2nd Edition, Research Studies Press, Hertfordshire, UK.

[3] Nokes, L. (1998) The Use of Low-Frequency Vibration Measurement in Orthopedics. Proceedings of the Institution of Mechanical Engineers, 213, 271-289. http://dx.doi.org/10.1243/0954411991534979

[4] Cunningham, J.L., Kenwright, J. and Kershaw, C.J. (1990) Biomechanical Measurement of Fracture Healing. Journal of Medical Engineering \& Technology, 14, 92-101. http://dx.doi.org/10.3109/03091909009015420

[5] Tower, S.S., Rodney, B.K. and Duwelius, P.J. (1993) Resonant Frequency Analysis of the Tibia as a Measure of Fracture Healing. Journal of Orthopaedic Trauma, 7, 552-557. http://dx.doi.org/10.1097/00005131-199312000-00011

[6] Nokes, L., Mintowt Czyzt, W.J., Fairclought, J.A., Makie, I. and Williams, J. (1985) Vibration Analysis in the Assessment of Conservatively Managed Tibial Fractures. Journal of Biomedical Engineering, 7, 40-44. http://dx.doi.org/10.1016/0141-5425(85)90007-X

[7] Benirschke, S.K., Mirels, H., Jones, D. and Tencer, A.F. (1993) The Use of Resonant Frequency Measurements for the Noninvasive Assessment of Mechanical Stiffness of the Healing Tibia. Journal of Orthopaedic Trauma, 7, 64-71. http://dx.doi.org/10.1097/00005131-199302000-00012

[8] Nakatsuchi, Y., Tsuchikane, A. and Nomura, A. (1996) Assessment of Fracture Healing in the Tibia Using the Impulse Response Method. Journal of Orthopaedic Trauma, 10, 50-62. http://dx.doi.org/10.1097/00005131-199601000-00008

[9] Cairns, N.J. (2010) The Feasibility of Vibration Analysis as a Technique to Detect Osseointegration of Transfemoral Implants. Ph.D. Thesis, Queensland University of Technology, Brisbane.

[10] Cairns, N.J., Adam, C.J., Pearcy, M.J. and Smeathers, J.E. (2011) Evaluation of Modal Analysis Techniques Using Physical Modelsto Detect Osseointegration of Implants in Transfemoral Amputees. IEEE Engineering in Medicine and Biology Society, 2011, 1600-1603.

[11] Dencker, H. and Moberg, E. (1968) Diagnosis of Soft-Tissue Interposition in Shaft Fractures of the Humerus and Femur by Measuring the Conduction of Vibration across the Fracture. Acta Chirurgica Scandinavica, 134, 540-542.

[12] Lappi, V.G., King, M.S. and May, I.L. (1979) Determination of Elastic Constants for Human Femurs. Journal of Biomechanical Engineering, 101, 193-197. http://dx.doi.org/10.1115/1.3426244

[13] Thomas, A.M.C., Luo, D.Z. and Dunn, J.W. (1991) Response of Human Femur to Mechanical Vibration. Journal of Biomedical Engineering, 13, 58-60. http://dx.doi.org/10.1016/0141-5425(91)90045-9

[14] Khalil, T.B., Viano, D.C. and Taber, L.A. (1981) Vibrational Characteristics of the Embalmed Human Femur. Journal of Sound and Vibration, 75, 417-436. http://dx.doi.org/10.1016/0022-460X(81)90387-4

[15] Misurya, R.K., Khare, A., Mallick, A., Sural, A. and Vishwakarma, G.K. (1987) Use of Tuning Fork in Diagnostic Auscultation of Fractures. Injury, 18, 63-64. http://dx.doi.org/10.1016/0020-1383(87)90391-3

[16] Jawad, Z., Odumala, A. and Jones, M. (2012) Objective Sound Wave Amplitude Measurement Generated by a Tuning Fork. An Analysis of Its Use as a Diagnostic Tool in Suspected Femoral Neck Fractures. Injury, 43, 835-837. http://dx.doi.org/10.1016/j.injury.2011.09.030

[17] Sundararajan, D. (2001) The Discrete Fourier Transform: Theory, Algorithms and Applications. World Scientific Publishing Company, Singapore.

[18] Jurist, J.M. (1970) In Vivo Determination of the Elastic Response of Bone-Method of Ulnar Resonant Frequency Determination. Physics in Medicine and Biology, 15, 417-426. http://dx.doi.org/10.1088/0031-9155/15/3/002

[19] Bediz, B., Özgüven, H.N. and Korkusuz, F. (2010) Vibration Measurements predict the Mechanical Properties of Human Tibia. Clinical Biomechanics, 25, 365-371. http://dx.doi.org/10.1016/j.clinbiomech.2010.01.002

[20] Van der Perre, G., Van Audekercke, R., Martens, M. and Mulier, J.C. (1983) Identification of In-Vivo Vibration Modes of Human Tibiae by Modal Analysis. Journal of Biomedical Engineering, 105, 244-248.

[21] Tsuchikane, A., Nakatsuchi, Y. and Nomura, A. (1995) The Influence of Joints and Soft Tissue on the Natural Frequency of the Human Tibia Using the Impulse Response Method. ARCHIVE: Proceedings of the Institution of Mechanical Engineers, 209, 149-155. http://dx.doi.org/10.1243/PIME_PROC_1995_209_337_02 
Scientific Research Publishing (SCIRP) is one of the largest Open Access journal publishers. It is currently publishing more than 200 open access, online, peer-reviewed journals covering a wide range of academic disciplines. SCIRP serves the worldwide academic communities and contributes to the progress and application of science with its publication.

Other selected journals from SCIRP are listed as below. Submit your manuscript to us via either submit@scirp.org or Online Submission Portal.
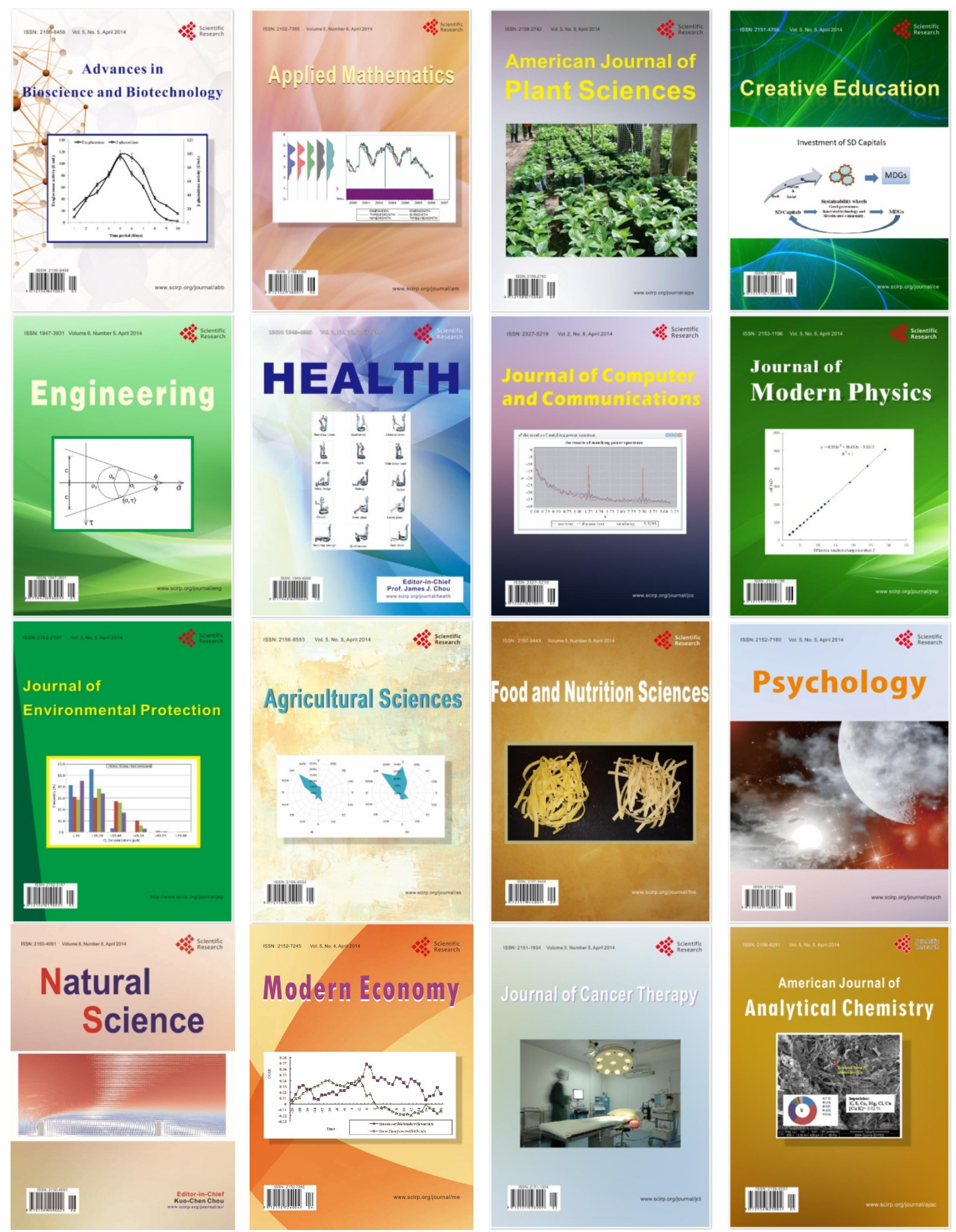